\section{Comparison between Fibroscan and Serum Taurine for Early Diagnosis of Liver Fibrosis in Egyptian Patients Infected with HCV}

Ibrahim El Agouza', Rabab Fouad ${ }^{2}$, Ramadan Ahmed ${ }^{3}$, Mohmmed El-Sayed ${ }^{2}$ and Amany Menshawy ${ }^{*}$

${ }^{1}$ Faculty of Science, Zoology Department, Cairo University, Egypt

${ }^{2}$ Endemic Medicine Department, Faculty of Medicine, Cairo University, Cairo, Egypt

${ }^{3}$ Hepatology Department, Ahmed Maher Teaching Hospital, Cairo, Egypt

*Corresponding author: Amany Menshawy, Faculty of Science, Zoology Department, Cairo University, Egypt, Tel: 01120070523; E-mail: Amany.Menshawy@gmail.com

Received date: May 22, 2017; Accepted date: May 27, 2017; Published date: June 02, 2017

Copyright: (C) 2017 Agouza IE, et al. This is an open-access article distributed under the terms of the Creative Commons Attribution License, which permits unrestricted use, distribution, and reproduction in any medium, provided the original author and source are credited.

\section{Abstract}

Aim: The aim is to evaluate the role of measuring serum taurine level as an early biomarker for detection and staging of hepatic fibrosis in comparison to Fibroscan.

Patients and methods: 70 patients who are positive HCV are classified into five groups according to the scoring of Fibroscan. 10 healthy subjects were also enrolled as control group. Full clinical examination and complete biochemical analysis in addition to fibroscan and serum taurine as new marker are performed for all the selected patients and volunteers.

Results: Results showed non-significant changes in the most Analytical data between the five groups of patients and control group, but a significant Increment in the serum level of ALT and AST in F4 Stage is noticed and marked decrease in platelets also found in F4. The most interesting point recorded is that Serum taurine levels were exhibited a value markedly lower than that recorded in control group and its decline was related to the severity of the diseases.

Conclusion: It is suggested that the assessment of taurine level in sera of all hepatic patients beside fibroscan are of great value in the early diagnosis of any fibrotic changes in liver.

Keywords: Hepatic elastography; Hepatitis C virus; Liver biopsy; Liver fibrosis; Serum taurine level

\section{Introduction}

Hepatitis C virus (HCV) in Egypt has the largest epidemic of the world with a percentage of $15-20 \%$, which is ten times greater than any other country [1-6]. The prevalence of HCV is highest in children and young adults who received parenteral anti-schistosomiasis treatment in the 1960s-1980s [7]. Egypt has the highest number of patients with genotype $4 \mathrm{HCV}$ more than $90 \%$ of infected patients [8]. The vast majority of those infected Patients with HCV have not received treatment [9]. Currently Egypt has the greatest burden of advanced liver disease from HCV worldwide, the estimates suggest that in Egypt in 2013, there were 770,000 persons with cirrhosis, 16,000 HCV-related HCC cases and 33,000 HCV-related to liver deaths [10]. Patients with hepatitis $\mathrm{B}$ and hepatitis $\mathrm{C}$ virus infections are at high risk for development of hepatic fibrosis that may eventually develop cirrhosis and hepatocellular carcinoma [11]. Liver fibrosis in chronic liver disease, is characterized by excessive accumulation of an extracellular matrix, in response to chronic inflammation. Chronic hepatitis $\mathrm{C}$ infection represents the most common cause of hepatic fibrosis in Egypt [12].

Liver biopsy remains an important tool in the evaluation and management of liver disease, but it has several limitations invasive test such as pain and bleeding. The sample resulting from liver biopsy is only a very small piece of the liver, which can lead to incorrect staging if this sample is not representative of the rest of the liver. Besides, different pathologists can interpret the same sample differently, which can result in discrepancies in liver disease staging [13].

To overcome these limitations, a new method for the staging of liver fibrosis is required. This technique must be non-invasive, fast, safe and reliable [14]. Transient elastography (TE) using Fibroscan is a relatively recent non-invasive method useful for staging of hepatic fibrosis [15]. TE was considered successful only if at least ten valid Measurements were performed on each patient. The success rate at least $60 \%$, and an interquartile range of $<30 \%$ of the value of the median performance of TE can be limited in obese patients also is impossible in patients with ascites. As TE waves cannot penetrate into ascites, older age and feature of the metabolic syndrome [16].

Taurine, 2-amino-ethanesulphonic acids, (Tau) an essential amino acid, present at high concentrations in the liver [17]. It has various physiological functions and protective properties including protection against various types of hepatic damage [18]. Tau has also been shown to have hepatoprotective effects that are often accompanied by reduced endoplasmic reticulum (ER) stress, oxidative stress, production of inflammatory, fibrogenic mediators and activation of stellate cells $[18,19]$. 
Page 2 of 6

Mice with hetero and homozygous knockout of the Tau transporter show chronic liver disease characterized by fibrosis, inflammation, and hepatocyte apoptosis [20]. Tau possesses anti-inflammatory and immune-regulatory properties [21]. In iron-potentiated alcoholic liver fibrotic rats, Tau restored mitochondrial function, prevented DNA damage and apoptosis. It reduced reactive oxygen species formation, curtailed the production of inflammatory and fibrogenic mediators and the activation of stellate cells $[19,22]$. More ever, it was suggested that assessment of taurine level in sera of patients with high risk for cancer breast or uterus are of great value in the early diagnosis of malignant changes in both organs $[23,24]$. and more recently it was advice to use serum taurine level in diabetic patients as a pre-early marker for diabetic retinopathy [25]. Also, it can induce apoptosis and inhibit the proliferation of HCC HepG2 cells [26] and induced apoptosis of human colon cancer [27]. Tau also could prevent the development of ameliorates glycemia, the action of insulin, and dyslipidemia in type 2 diabetes mellitus (T2DM) [28]. Another study showed that post-treatment supplemention of taurine is recommended for T2DM [29].

Several studies have demonstrated that exogenous supplementation with Tau can prevent liver injury caused by different harmful substances as well as inhibit extracellular matrix (ECM) molecules deposition on the damaged liver and stop the process of liver fibrosis, protect hepatic tissue and hepatocytes against various substrates, inducing hepato toxicities, oxidative stress, and hepato carcinogenesis $[18,20,30,31]$. Recently, taurine was used to ameliorate hepatotoxic effect of dinitrotoluene in rats [32].

\section{Patients and Methods}

All the patients first received information on the study from their referring physician and were asked to sign an informed consent form. This study included 70 patients aged between 29-65 years (males and females), were selected from our patient's clinics at the Hepatology department, Ahmed Maher Teaching Hospital, Cairo, Egypt.

Those patients presented with abdominal troubles and signs of liver impairment, and we rejected all patients presented with kidney impairment or diabetes. They were classified into 5 groups according to the scoring of Fibroscan. 10 healthy subjects were also enrolled as control group.

TE qualities were further changed over in the comparing semi quantitative fibrosis score of METAVIR. It is based on a semi quantitative 5-point scale from 0 to 4 : F0, the absence of parenchymal fibrosis; F1 enlarged fibrotic portal tract; F2, periportal or initial portal-portal septa but intact architecture; F3, architectural distortion but no obvious cirrhosis; and F4, cirrhosis. The conversion of TE values into the corresponding METAVIR stage was made by means of validated cutoff values (i.e., $\mathrm{F} 0-\mathrm{F} 1=2.4-7 \mathrm{kPa}, \mathrm{F} 2=7.1-9.5 \mathrm{kPa}$, $\mathrm{F} 3=9.6-12.5 \mathrm{kPa}$ and F4 N $12.5 \mathrm{kPa}$ ) The change of TE values into the relating METAVIR stage was made by means of validated cutoff values $[33,34]$. The patients and volunteers were classified as follows:

- Control group ( $\mathrm{No}=10$ healthy subjects)
- Stage 0 group ( $\mathrm{No}=10$ patients)

- Stage 1 group ( $\mathrm{No}=12$ patients)

- Stage 2 group ( $\mathrm{No}=13$ patients)

- Stage 3 group ( $\mathrm{No}=15$ patients)

- Stage 4 group ( $\mathrm{No}=20$ patients)

Full clinical examination, complete biochemical analysis (including liver and complete blood picture and TSH). Virus detection done by the polymerase chain reaction (PCR), Fibroscan was measured for all patients and control after 12 hours fasting. For the whole selected subjected, after 12 hours fasting, $10 \mathrm{ml}$ of venous blood was collected, in plain tube and allowed to clot for $1 / 2$ an hour, after which it was centrifuged at $3,000 \mathrm{rpm}$ for $10 \mathrm{~min}$. The serum was separated and stored at $-20^{\circ} \mathrm{C}$ to avoid loss of biological activity until the batch analysis for serum taurine. It was mesasured by high performance liquid chromatography (HPLC) according to pre-Colum extraction and derivatization methodology [35].

TE was done with FibroScan (Echosens, Paris, France) using a normal probe (no XL probe was used), this measurement is taken on the right lobe of the liver, through intercostals spaces with the patient lying in dorsal decubitus with the right arm in maximal abduction. The tip of the transducer probe is covered with coupling gel and placed on the skin, between the rib bones at the level of the right lobe of the liver. TE measures liver stiffness in a volume that approximates a cylinder 1 $\mathrm{cm}$ wide and $4 \mathrm{~cm}$ long, between $25 \mathrm{~mm}$ and $65 \mathrm{~mm}$ below the skin surface. This volume is at least 100 times bigger than a biopsy sample, and is therefore far more representative of the hepatic Parenchyma, a cut-off of $<5.5 \mathrm{kPa}$ was considered to indicate normal [15].

\section{Statistical Analysis}

After confirmation of normal distribution for all variables, the significance of differences was evaluated by paired t-test or analysis of variance (ANOVA). Relationships between variables were analyzed by simple correlation analysis. Data are expressed as mean SD, and a value of $\mathrm{P}<0.05$ was the criterion for statistical significance.

\section{Results}

Our study includes 70 patients (36 male and 34 female) Those patients were classified into five groups according the degree of fibrosis including (F0, F1, F2, F3, F4), beside 10 healthy subject's Negative PCR for HCV were enrolled as control group.

Only those patients who had reliable Fibroscan were taken for analysis. A total of 76 patients were enrolled in the study. Of 76 patients, six had unreliable Fibroscan so a total of 70 patients were included in analysis.

For the hematological parameters the results showed nonsignificant changes $(\mathrm{P}>0.05)$ in haemoglobin $(\mathrm{Hb})$, Red blood cells (RBCs), White blood cells (WBCs) and platelets in all groups as shown in Table 1. Only significant change in the platelets count was recorded between $\mathrm{f} 3$ and $\mathrm{f} 1(\mathrm{P}<0.00)$, and also between $\mathrm{f} 4$ and $\mathrm{f} 1(\mathrm{P}<0.000)$.

\begin{tabular}{|l|l|l|l|l|}
\hline Group & Hb g/dl & RBCs $10^{6} / \mathbf{c m m}$ & WBCs 10 $/ \mathbf{c m m}$ & Platelets $10^{3} / \mathbf{c m m}$ \\
\hline Control $(n=10)$ & $13.30 \pm 1.00$ & $4.33 \pm 0.27$ & $6.00 \pm 1.12$ & $243.70 \pm 31.59$ \\
\hline F0 $(n=10)$ & $12.52 \pm 1.56$ NS & $4.23 \pm 0.52$ NS & $6.48 \pm 1.98$ NS & $218.60 \pm 40.04$ NS \\
\hline
\end{tabular}


Citation: Agouza IE, Fouad R, Ahmed R, Sayed ME, Menshawy A (2017) Comparison between Fibroscan and Serum Taurine for Early Diagnosis of Liver Fibrosis in Egyptian Patients Infected with HCV. Clin Med Biochem 3: 127. doi:10.4172/2471-2663.1000127

Page 3 of 6

\begin{tabular}{|l|l|l|l|l|}
\hline$F 1(n=12)$ & $12.88 \pm 1.34$ NS & $4.38 \pm 0.41$ NS & $5.73 \pm 1.81 \mathrm{NS}$ & $240.67 \pm 58.15 \mathrm{NS}$ \\
\hline F2 $(n=13)$ & $12.70 \pm 1.79 \mathrm{NS}$ & $4.25 \pm 0.56 \mathrm{NS}$ & $6.68 \pm 1.41 \mathrm{NS}$ & $224.38 \pm 82.07 \mathrm{NS}$ \\
\hline F3 $(n=15)$ & $13.45 \pm 1.42 \mathrm{NS}$ & $4.47 \pm 0.45 \mathrm{NS}$ & $4.87 \pm 1.35 \mathrm{~d}^{*}$ & $174.20 \pm 43.49 \mathrm{a}, \mathrm{c}^{* *}, \mathrm{~d}^{*}$ \\
\hline F4 $(n=20)$ & $13.36 \pm 1.03 \mathrm{NS}$ & $4.40 \pm 0.39 \mathrm{NS}$ & $4.64 \pm 1.21$ a. b, c, $\mathrm{d}^{*}$, e ns & $157.80 \pm 45.26 \mathrm{a}, \mathrm{c}^{* * *}, \mathrm{~b}, \mathrm{~d}^{* *}, \mathrm{e} \mathrm{ns}$ \\
\hline
\end{tabular}

Table 1: Blood picture in different groups of patients. Data are expressed as mean \pm SD. a: refers to control group, b: refers to stage 0 group, c: refers to stage 1 group, d: refers to stage 2 group, e: refers to stage 3 group. $\mathrm{p}$ value $>0.05$ Non-significant (ns), ${ }^{*}$ Significant at level $<0.01,{ }^{* *}$ highly Significant at level $<0.00,{ }^{* * *}$ very highly Significant $<0.000$ p value 0.01 to 0.05 Significant ${ }^{*}$, p value 0.001 to 0.01 High significant ${ }^{* *}$, p value 0.0001 to 0.001 Extremely significant ${ }^{* *}$.

Moreover Table 2 showed non-significant changes $(\mathrm{P}>0.05)$ in the different fibrotic groups and control. A significant Increment in the (Alanine transaminase (ALT), Aspartate transaminase (AST), total bilirubin, Albumi, the international normalized ratio (INR) between

\section{serum level of ALT and AST in F4 Stage is noticed.}

\begin{tabular}{|l|l|l|l|l|l|}
\hline Group & ALT U/L (0-50) & AST U/L (0-40) & Total bilirubin mg/dl (0-1) & Albumin g/dl (3.5-5.5) & INR (1-1.3) \\
\hline Control $(n=10)$ & $25.00 \pm 2.98$ & $22.40 \pm 3.44$ & $0.81 \pm 0.11$ & $4.37 \pm 0.18$ & $1.01 \pm 0.14$ \\
\hline F0 $(n=10)$ & $41.20 \pm 18.43 \mathrm{NS}$ & $47.50 \pm 19.46 \mathrm{NS}$ & $0.67 \pm 0.25 \mathrm{NS}$ & $3.87 \pm 0.20 \mathrm{NS}$ & $1.03 \pm 0.85 \mathrm{NS}$ \\
\hline F1 $(n=12)$ & $41.08 \pm 11.65 \mathrm{NS}$ & $48.50 \pm 18.92 \mathrm{NS}$ & $0.93 \pm 0.21 \mathrm{NS}$ & $3.94 \pm 0.31 \mathrm{NS}$ & $1.08 \pm 0.08 \mathrm{NS}$ \\
\hline F2 $(n=13)$ & $45.31 \pm 20.06 \mathrm{NS}$ & $52.54 \pm 21.06 \mathrm{a}^{* *}$ & $1.00 \pm 1.01 \mathrm{NS}$ & $4.08 \pm 0.48 \mathrm{NS}$ & $1.08 \pm 0.18 \mathrm{NS}$ \\
\hline F3 $(n=15)$ & $52.33 \pm 31.04 \mathrm{a}^{*}$ & $54.20 \pm 25.33 \mathrm{a}^{* *}$ & $1.03 \pm 0.51 \mathrm{NS}$ & $3.97 \pm 0.53 \mathrm{a}^{*}$ & $1.11 \pm 0.19 \mathrm{NS}$ \\
\hline F4 $(n=20)$ & $61.30 \pm 47.43 \mathrm{a}^{* * *}$ & $67.80 \pm 38.08 \mathrm{a}^{* * *}$ & $0.87 \pm 0.24 \mathrm{NS}$ & $3.68 \pm 0.33 \mathrm{a}^{* * *}, \mathrm{~d}, \mathrm{e}^{* *}, \mathrm{c}^{*}$ & $1.07 \pm 0.32 \mathrm{NS}$ \\
\hline
\end{tabular}

Table 2: Liver functions and INR in different groups of patients. Data are expressed as mean \pm SD. a: refers to control group, b: refers to stage 0 group, c: refers to stage 1 group, d: refers to stage 2 group, e: refers to stage 3 group, p value $>0.05$ Non-significant(ns), ${ }^{*}$ Significant at level $<0.01$, ${ }^{* *}$ highly Significant at level $<0.00,{ }^{* * *}$ very highly Significant $<0.000, \mathrm{p}$ value 0.01 to 0.05 Significant ${ }^{*}, \mathrm{p}$ value 0.001 to 0.01 High significant ${ }^{* *}, \mathrm{p}$ value 0.0001 to 0.001 Extremely significant ${ }^{* * *}$

There was a significant difference in median LSM value in patients with F0 $(4.70 \pm 0.58)$ in comparison to patients having mild fibrosis (F1 $6.29 \pm 0.61$, F2 $8.11 \pm 0.74)$ and advanced fibrosis (F3, F4) (10.92 \pm
0.96 vs. $24.18 \pm 15.44)$. The difference between median LSM value of mild and advanced fibrosis was also statistically significant.

\begin{tabular}{|c|c|c|c|c|}
\hline Group & TSH ulU/MI 0.305 .00 & PCR IU/mL Less than 16 & Fibroscan kPa 0-75 & Taurine $\mu \mathrm{mol} / \mathrm{L}$ Up to 55 \\
\hline Control $(n=10)$ & $1.05 \pm 0.70$ & Less than 16 & $00 \pm 00$ & $62.50 \pm 3.37$ \\
\hline $\begin{array}{l}\text { F0 } \\
(n=10)\end{array}$ & $1.69 \pm 1.66 \mathrm{NS}$ & $569693.3 \pm 326391.1 \mathrm{a}^{* * *}$ & $4.70 \pm 0.58 a^{* \star *}$ & $40.63 \pm 3.88 a^{\star \star \star}$ \\
\hline $\begin{array}{l}F 1 \\
(n=12)\end{array}$ & $1.53 \pm 1.03 \mathrm{NS}$ & $692273.6 \pm 769579.5 a^{* \star \star}$ & $6.29 \pm 0.61 \mathrm{a}, \mathrm{b} \mathrm{ns}$ & $33.52 \pm 2.35 a, b^{* \star *}$ \\
\hline $\begin{array}{l}F 2 \\
(n=13)\end{array}$ & $1.61 \pm 0.97 \mathrm{NS}$ & $699066.5 \pm 1322773 a^{\star \star \star}$ & $8.11 \pm 0.74 a^{*}, b, c$ ns & $28.17 \pm 4.08 \mathrm{a}, \mathrm{b}^{* \star \star}, \mathrm{c}^{*}$ \\
\hline $\begin{array}{l}\text { F3 } \\
(n=15)\end{array}$ & $1.72 \pm 1.44 \mathrm{NS}$ & $1467885 \pm 1957105 a^{* \star *}$ & $10.92 \pm 0.96 a^{* *}, b, c, d n s$ & $24.44 \pm 1.56 a, b, c^{* * *}, d^{*}$ \\
\hline $\begin{array}{l}F 4 \\
(n=20)\end{array}$ & $2.31 \pm 0.97 \mathrm{NS}$ & $3124404 \pm 8163084 \mathrm{a}, \mathrm{b}, \mathrm{c}, \mathrm{d}, \mathrm{e}^{* * *}$ & $24.18 \pm 15.44 a, b, c, d, e^{* * *}$ & $20.64 \pm 2.77 \mathrm{a}, \mathrm{b}, \mathrm{c}, \mathrm{d}^{* * *}, \mathrm{e}^{* *}$ \\
\hline
\end{tabular}

Table 3: TSH, PCR, Fibroscan, Taurine in different groups of patients. Data are expressed as mean \pm SD. a: refers to control group, b: refers to stage 0 group, c: refers to stage 1 group, d: refers to stage 2 group, e: refers to stage 3 group, p value $>0.05$ Non-significant (ns), ${ }^{*}$ Significant at level 
$<0.01,{ }^{* *}$ highly Significant at level $<0.00,{ }^{* * *}$ very highly Significant $<0.000$, p value 0.01 to 0.05 Significant ${ }^{*}$, p value 0.001 to 0.01 High significant ${ }^{* *}$, p value 0.0001 to 0.001 Extremely significant ${ }^{* *}$.

The most interesting point in this work was illustrated in Table 3 when the serum level of taurine recorded in F0 was highly significantly decreased $(40.63 \pm 3.88)$ regarding to its level recorded in control group $(62.50 \pm 3.37)$. This level was decreased parallel to the degree of fibrosis from F1 $(33.52 \pm 2.35)$ To F2 $(28.17 \pm 4.08)$ To F3 $(24.44 \pm$ 1.56) Up to F4 (20.64 \pm 2.77$)$.

\section{Discussion}

Chronic hepatitis $\mathrm{C}$ remains a worldwide problem with highly prevalence rates in developing countries. Egypt, for example, the prevalence approaches $20 \%$ of a 90 million population [1-6]. Also has the highest number of Patients with genotype $4 \mathrm{HCV}$ more than $90 \%$ of infected patients [8]. Till now Liver biopsy is considered the gold standard technique for the evaluation of liver fibrosis. But there are many drawbacks of liver fibrosis like invasive test, pain and bleeding [13]. To avoid this limitation, we measured liver stiffness by TE using fibroscan device to assess the different degree of liver fibrosis (F0, F1, F2, F3, F4). This device is non-invasive, safe and reliable [14]. But it is value is limited in obese patients also is impossible in patients with ascites. As TE waves cannot penetrate into ascites, older age and feature of the metabolic syndrome [16].

Our result showed no significant change in Liver enzymes. Confirming our result there are reports of marked fibrosis (5\%-30\%)and even cirrhosis (1.3\%) in persons with normal ALT value [36,37]. While taurine levels were exhibited a value markedly lower than control group according to the severity of the diseases that consider as early diagnosis and more accurate than other routine test like AST, ALT, Platelets. There is a study exploring the relationship between plasma amino acid profiles and liver fibrosis, it is clearly demonstrated that abnormal sulfur containing amino acids (SAA) patterns in patients with chronic hepatitis $\mathrm{C}$ are correlated with the progression of liver fibrosis [38]. Tau as an antioxidant can increase hepatic self-antioxidant capacities and decreased lipid peroxidation in high-fat/cholesterol dietary hamsters. Taurine supplementation can reduce serum glutamic oxaloacetic transaminase (GOT) and glutamic pyruvic transaminase (GPT) [39].

Taurine not only can act as a direct antioxidant by scavenging free radicals and inhibiting lipid peroxidation (LPO), it also can stimulate the activity cytoprotective enzymes when the cell is exposed to stressful conditions [40]. The hepatic cell membrane can automatically repair after alcohol withdrawal if the damage is not serious, while taurine accelerates the repair of hepatic cells, decreasing membrane permeability and inhibiting the release of ALT and AST and improve the serum levels bilirubin $[29,41]$. Moreover, taurine supplementation also could downregulate these granulomatous and fibrogenic mediators in the liver of $S$. japonicum-infected mice which further confirmed the anti-granulomatous and anti-fibrotic effects of taurine during $S$. japonicum infection [42]. In acute liver disease model in a rat induced by a single administration of $\mathrm{CCl}_{4}$, showed that taurine treatment prevented hepatocellular necrosis, lipid peroxidation, mitochondrial abnormalities. Moreover, taurine also inhibits the transformation of $\mathrm{HSCs}$ induced by $\mathrm{CCl}_{4}$ observed by electron microscopy [29]. Taurine significantly decreased hepatic fibrosis and fibrogenesis of isolated hepatic stellate cells, which are converted to myofibroblasts by oxidative stress in cirrhotic liver, through inhibition of transforming growth factor- $\beta$ expression. In $\mathrm{CCl}_{4}$-administered rats, the taurine concentration in the liver, plasma, and other tissues was significantly decreased [43].

Taurine may be used in combination with Silymarine as an additional adjuvant therapy to cure liver diseases induced by $\mathrm{CCl}_{4}$ such as cirrhosis and viral hepatitis [44].

Regarding fibroscan, our result showed that the median stiffness values increased as the fibrosis stage increase. but there some factors associated with reading unreliability were BMI $>30 \mathrm{~kg} / \mathrm{m}^{2}$ in our study we could not do TE in four patients due to obesity their BMI is greater than $32 \mathrm{~kg} / \mathrm{m}^{2}$. It postulated that in population as in our country high proportion of patients have $\mathrm{BMI}>30 \mathrm{~kg} / \mathrm{m}^{2}$, elastometry should be difficult to use because it could overestimate liver fibrosis in a high proportion of patients [45]. Also, TE Failure in two patients as no valid shot after at least ten attempts.

The most attracted point is when fibroscan diagnosis patients at f0 usually regular check-up is the only advice from doctor to all patients have stage zero of stiffness. But in contrast, the most impressive observation in our work is the result of antioxidant taurine which showed highly significant decrease in their serum levels in all patients staging zero $(40.63 \pm 3.88)$ when compared to normal control group $(62.50 \pm 3.37)$ which can be consider as an early sign of liver impairment and the immediate induction of its treatment. The classification of Fibroscan will be enhanced by Taurine level measurements. Within each Fibroscan class, the taurine can play an important to measure any slight deterioration that may happen in the patient's status. In case of dealing with patients classified as f0, the taurine level may represent another real evaluation of the possibility of patient's deterioration as shown in this study. It has been shown that the taurine level can detect any slight shift from the normal case which may anticipate any future liver problem. It was postulated that patients with stages F0-F1 are considered much less likely to progress and may be spared from treatment, and Patients with stage F2-F4 have a higher chance of development of cirrhosis within the following 5-10 years and are considered eligible for treatment [46]. In stage F4 the stiffness of fibroscan range between 12.6-64.0 that is very wide range. While taurine level in this stage is $20.64 \pm 2.77$.

In our study patients with F4 stiffness of fibroscan between (12.6-64.0) as shown in Table 3, that high stiffness of patients may be highly susceptibility for cancer. TE value was selected as one of independent risk factors for HCC development, and patients with higher value had significantly higher risk of HCC development [47].

Previous research showed stage F4 Fibrosis is important differentiating mark, where patients with cirrhosis need closer monitoring, screening for varices and HCC is recommended, response to therapy is diminished, and these patients may not tolerate many drugs involved in the treatment of HCV [46]. There is no doubt that taurine is considered as powerful hepatoprotective substance that can protect the hepatocyte through different mechanisms $[31,48,49]$.

Our result encourages us form new classification for cirrhotic patients depend on taurine level. Hepatic patients consider safety when taurine level above $50 \mu \mathrm{mol} / \mathrm{L}$, when taurine level exhibited value between (40-50) hepatic patients are highly susceptible for many 
hepatic complication, advanced liver cirrhosis and susceptibility for $\mathrm{HCC}$ increased when taurine level decreased than $30 \mu \mathrm{mol} / \mathrm{L}$.

A lot of paper consider $20 \mu \mathrm{mol} / \mathrm{L}$ of taurine level as a cut of value of tumour by other means any patients exhibited less than $20 \mu \mathrm{mol} / \mathrm{L}$ must be suffer from cancer in elsewhere of body $[23,24,26,27]$. Because they suggested that taurine is high sensitive nonspecific tumour marker.

So, taurine level may be represented an early alarm predictive tool in patients suffering from liver complications. Taurine level may play a complementary important role with the Fibroscan to monitor the patient's status and progress within each class of fibroscan. In other word, within each fibroscan class, many subclasses may be generated according to the taurine level. This may be measure whether the patients within a class is stable or is deteriorating. So, integrating both the Fibroscan and Taurine level measurement may result in a more accurate and direct monitoring of the patient status. It may represent a warning for the physician to take the suitable action.

In conclusion based on the results of the present investigation, we strongly suggested the assessment of serum taurine level in all hepatic patients especially +ve $\mathrm{B}$, +ve $\mathrm{C}$ beside fibroscan and biochemical analysis especially in $\mathrm{F} 4$ because those patients are highly susceptible for HCC. So, we must not let patients reach to such a high score of fibrosis, we suggest giving them especial dose of taurine as hepatoprotective drug in F0 stage.

\section{References}

1. El-Zanaty F, Way A (2006) Egypt demo-graphic and health survey 2008 Cairo, Egypt. Ministry of Health, El-Zanaty and Associates, and Macro International.

2. Guerra J, Garenne M, Mohamed MK (2012) HCV burden of infection in Egypt: results from a nationwide survey. J Viral Hepat 19: 560-567.

3. Cuadros DF, Branscum AJ, Miller FD (2017). Spatial epidemiology of hepatitis $\mathrm{C}$ virus infection in Egypt: analyses and implications. Hepatology 60: 1150-1159.

4. Reker C, Islam KM (2014) Risk factors associated with high prevalence rates of hepatitis C infection in Egypt. Int J Infect Dis 25: 104-106.

5. Kim DD, Hutton DW, Raouf AA (2015) Cost-effectiveness model for hepatitis $\mathrm{C}$ screening and treatment: Implications for Egypt and other countries with high prevalence. Glob Public Health 10: 296-317.

6. Benova L, Awad SF, Miller FD (2015) Estimation of hepatitis C virus infections resulting from vertical transmission in Egypt. Hepatology 61: 834-842.

7. Gower E, Estes CC (2014) Global epidemiology and genotype distribution of the hepatitis $\mathrm{C}$ virus. J Hepatol 61: 45-57.

8. Frank C, Mohamed MK, Strickland GT (2000) The role of parenteral antischistosomal therapy in the spread of hepatitis $\mathrm{C}$ virus in Egypt. Lancet 355: 887-891.

9. Dore GJ, Ward J, Thursz M (2014) Hepatitis C disease burden and strategies to manage the burden. J Viral Hepat 21: 1-4.

10. Doss W, Shiha G, Hassany M (2015) Sofosbuvir Plus Ribavirin for Treating Egyptian Patients with Hepatitis C Genotype 4. J Hepatol 63: 581-585.

11. Taouli B, Tolia AJ, Losada M (2007) Diffusion-weighted MRI forquantification of liver fibrosis: preliminary experience. AJR Am J Roentgenol 189: 799-806.

12. Brodsky SV, Mendelev N, Melamed M, Ramaswamy G (2007) Vascular density and VEGF expression in hepatic lesions. J Gastrointestin Liver Dis 6: 373-377.

13. Afdhal NH (2012) Fibroscan (transient elastography) for the measurement of liver fibrosis. Gastroenterol Hepatol 8: 605-607.
14. Kovac JD, Dakovic M, Stanisavljevic D, Alempijevic T (2012) Diffusionweighted MRI versus transientelastography in quantification of liver fibrosis in patients withc hronic cholestatic liver diseases. Eur J Radiol 81: 2500-2506.

15. Castera L, Vercinol J (2005) Prospective Comparison of Transient Elastography, Fibrotest, APRI, and Liver Biopsy for the Assessment of Fibrosis in Chronic Hepatitis C. Gastroenterology 128: 343-350.

16. Castera L, Foucher J, Bernard PH (2010) Pitfalls of liver stiffness measurement: A 5-years prospective study of 13,369 examinations. Hepatology 51: 828-835.

17. Batista TM, Ribeiro RA, da Silva PM (2013) Taurine supplementation improves liver glucose control in normal protein and malnourished mice fed a highfat diet. Mol Nutr Food Res 57: 423434.

18. Gentile CL, Nivala AM, Gonzales JC (2011) Experimental evidence for therapeutic potential of taurine in the treatment of nonalcoholic fatty liver disease. Am J Physiol Regul Integr Comp Physiol 301: 1710-1722.

19. Devi SL, Viswanathan P, Anuradha CV (2010) Regression of liver fibrosis by Taurine in rats fed alcohol: effects on collagen accumulation, selected cytokines and stellate cell activation. Eur J Pharmacol 647: 161-170.

20. Warskulat U, Borsch E, Reinehr R (2006) Chronic liver disease is triggered by taurine transporter knockout in the mouse. FASEB J 20: 574-576.

21. De Luca A, Pierno S, Camerino DC (2015) Taurine: the appeal of a safe amino acid for skeletal muscle disorders. J Transl Med 13: 243.

22. Devi SL, Anuradha CV (2010) Mitochondrial damage, cytotoxicity and apoptosis in ironpotentiated alcoholic liver fibrosis: amelioration by taurine. Amino Acids 38: 869-879.

23. El Agouza IM, Eissa SS, El Houseini MM (2011) Taurine: a novel tumor marker for enhanced detection of breast cancer among female patients. Angiogenesis 14: 321330.

24. ELAgouza IM, Nashar DE (2011) Serum Taurine as a Marker of Endometrial Cancer. The Open Women's Health Journal 5: 1-6.

25. Agouza IME, Saad AH, Mahfouz AA, Hamdy K (2017) Serum Taurine Level in Relation to Ophthalmoscopic Examination as Early Marker for Diabetic Retinopathy. Clin Med Biochem 3: 124.

26. Tu S, Zhang X, Luo D (2015) Effect of taurine on the proliferation and apoptosis of human hepatocellular carcinoma HepG2 cells. Experimental and Therapeutic Medicine 10: 193-200.

27. Zhang X, Tu S, Wang Y, Xu B, Wan F, et al. (2014) Mechanism of taurineinduced apoptosis in human colon cancer cells. Acta Biochim Biophys Sin (Shanghai) 46: 261272.

28. Santos-Silva JC, Ribeiro RA, Vettorazzi JF (2015) Taurine supplementation ameliorates glucose homeostasis, prevents insulin and glucagon hypersecretion, and controls b, a, and d-cell masses in genetic obese mice. Amino Acids 47: 1533-1548.

29. Foda DS, Farrag EK, Metwally NS (2016) Protective and therapeutic impact of taurine on some biochemical, immunological and histological parameters in diabetic rats. Journal of Applied Pharmaceutical Science 6: 45-54.

30. Miyazaki T, Karube M, Matsuzaki Y (2005) Taurine inhibits oxidative damage and prevents fibrosis in carbon tetrachloride-induced hepatic fibrosis. J Hepatol 43: 117-125.

31. Devi SL, Viswanathan P, Anuradha CV (2009) Taurine enhances the metabolism and detoxification of ethanol and prevents hepatic fibrosis in rats treated with iron and alcohol. Environ Toxicol 27: 120-126.

32. Azazy AE, El Agouza IM, Sherif MS, Mustafa AE (2016) Ameliratative effect of Taurine on dinitrotoluene induction in liver and kidney function of male rats. Advances in Natural Science Theory and Application 5: 70-78.

33. Rinaldi L, Restivo L, Guerrera B (2014) Hepatic steatosis and necroinflammatory activity over estimate liver stiffness by transient elastography in staging liver fibrosis in chronic hepatitis C. J Hepat Res 1012-1016. 
Citation: Agouza IE, Fouad R, Ahmed R, Sayed ME, Menshawy A (2017) Comparison between Fibroscan and Serum Taurine for Early Diagnosis of Liver Fibrosis in Egyptian Patients Infected with HCV. Clin Med Biochem 3: 127. doi:10.4172/2471-2663.1000127

Page 6 of 6

34. Brescini L, Orsetti E, Gesuita R (2014) Evaluating liver fibrosis by transient elastometry in patients with HIV-HCV coinfection and mono infection. Hepat e15426.

35. McMahon GP, O’Kennedy R, Kelly MT (1996) High-performance liquid chromatographic determination of ne in human plasma using precolumn extraction and derivatization. Pharm Biomed Anal 148: 1287-1294.

36. Puoti C, Castellacci R, Montagnese F (2000) Hepatitis C virus carriers with persistently normal aminotransferase levels: healthy people or true patients? Dig Liver Dis 32: 634-643.

37. Puoti C, Guido M, Mangia A, Persico M, Prati D (2003) Clinical management Of HCV carriers with normal aminotransferase levels. Dig Liver Dis 35: 362-369.

38. Zhang Q, Takahashi M, Noguchi Y (2006) Plasma amino acid profiles applied for diagnosis of advanced liver fibrosis in patients with chronic hepatitis C infection. Hepatol Res 34: 170-177.

39. Chang YY, Chou CH, Chiu CH (2011) Preventive effects of taurine on development of hepatic steatosis induced by a high-fat/cholesteroldietary habit. J Agri Food Chem 59: 450-457.

40. El-Sayed WM, Al-Kahtani MA, Abdel-Moneim AM (2011) Prophylactic and therapeutic effects of taurine against aluminum-induced acute hepatotoxicity in mice. J Hazar Mat 192: 880-886.

41. Wu G, Tang R, Yang J (2015) Taurine Accelerates Alcohol and Fat Metabolism of Rats with Alcoholic Fatty Liver Disease, Taurine 9. Adv Exp Med Biol pp: 793-805.
42. Yu YR, Ni XQ, Huang J (2016) Taurine drinking ameliorates hepatic granuloma and fibrosis in mice infected with Schistosoma japonicum. Int J Parasitol: Drug and Drug Res 6: 35-43.

43. Miyazaki T, Matsuzaki Y, Ikegami T (2004) The harmful effect of exercise on reducing taurine concentration in the tissues of rats treated with $\mathrm{CCl} 4$ administration. J Gastro enterol 39: 557-562.

44. Abdel-Moneim AM, Al-kahtani AM, El-kersh MA, Al Omair MA (2015) Free Radical-Scavenging, Anti-Inflammatory/Anti-Fibrotic and Hepatoprotective Actions of Taurine and Silymarin against CCl4 Induced Rat Liver Damage. PLOS ONE 11: e0144509.

45. Bonnard P, Elsharkawy A, Zalata K (2014) Comparison of liver biopsy and noninvasive techniques for liver fibrosis assessment in patients infected with HCV-genotype 4 in Egypt. J Viral Hepat 22: 245-53.

46. Ghany MG, Strader DB, Thomas DL, Seeff LB (2009) Diagnosis, management, and treatment of hepatitis C. An update. Hepatol 49: 1335-1374.

47. Masuzaki R, Tateishi R, Yoshida H (2009) Prospective risk assessment for hepatocellular carcinoma development in patients with chronic hepatitis C by transient elastography. Hepatol 49: 1954-1961.

48. El Agouza IM, ElNashar DE, Eissa SS (2010) The Possible Ultra Structural Ameliorative Effect of Taurine in Rat's Liver Treated with Monosodium Glutamate (MSG). The Open Hepatol J 2: 1-9.

49. El-Houseini ME, El-Agouza IM (2017) Novel protective role of curcumin and taurine combination against experimental hepatic arcinogenesis. Experimental and Therapeutic Medicine 13: 29-36. 